than in those without $(85.3 \%$ vs. $54.8 \% ; \mathrm{p}=0.007)$. No differences were observed according to the shared epitope and the frequency of HLA-DR4. The different TNF-a polymorphisms were equally distributed in AKA positive and negative populations. No significative radiological differences (presence of erosive disease and Larsen score) were observed at study entry between both populations. A trend to a more progressive radiological damage was observed at the end of follow-up. $(32 \pm 6 \mathrm{mo})$ in those patients with AKA, although the differences were no significative (Larsen score of $6.1 \pm 4.3$ in $\mathrm{AKA}(+)$ vs. $4.5 \pm 5.5$ in AKA (-). This trend is also observed when only RF positive patients were evaluated.

Conclusion These results indicate that AKA cannot identify a distinct immunogenetic subgroup in Spanish reumatoid population. The role of AKA as a possible marker of a more aggressive joint disease merits further investigation.

\section{THU0162 BONE INVOLVEMENT IN GAUCHER DISEASE}

ME Bahri, S Othmani, F Msaddek, B Louzir, MO Bahri. Internal Medicine Service, Military Hospital, Tunis, Tunisia

10.1136/annrheumdis-2001.1064

\section{Background}

Objectives

Methods Gaucher disease (GD) is an autosomal disorder of glycosphingolipid metabolism due to deficiency of the lysosomal acid glucocerebrosidase. Although prevalent among Ashkenazi jews, it has been described in all other ethnic groups. Bone lesions are associated with type 1 and type 3 GD. They are secondary to the progressive accumulation of histiocytes and macrophages laden with glucosylceramide in bone marrow. Expression of skeletal involvement in Gaucher patients ranges from asymptomatic disease, with or without radiologic signs, to symptomatic disease, which can be severe and engender considerable pain and disability. MRI appears to be the most valuable imaging technique for evaluating bone marrow involvement. Splenectomy is suggested to accelerate skeletal deterioration. Our patient was a 23-year old man type 1 GD who was admitted for evaluation of hepatosplenomegaly and thrombocytopenia. He also complained of episodic joint involving both knees, shoulders, wrists and elbows lasting $2-5$ days that started a year before admission. The pain was defined as non specific pain. Clinical examination yielded local tenderness. Hepatosplenomegaly was confirmed by abdominal CT scan. Biology revealed an hypersplenism (anaemia, thrombocytopenia) and polyclonal hypergammaglobulinemia. $\mathrm{X}$ ray of femurs and humerus showed a metaphysal multicystic osseous changes with endosteal cortical erosions. X ray of pelvis showed an osteosclerosis of iliac bones, lytic process of pubis symphysis and pathological fracture of both ischiopubian bones. MRI showed medullar bone infiltration in femurs, pelvis and humerus. $99 \mathrm{mTc}$ bone scan was normal. On liver as well as on bone marrow biopsy examination, Gaucher's cell infiltrates were detected. The level of leukocyte acid beta-glucosidase activity was very low. Hypersplenism was the indication for splenectomy. The weight of the resected spleen was $1950 \mathrm{gr}$; Following surgery, the patient noted an exacerbation of major joint pain and bone pain involving both femurs and humerus which improve after one week of non steroidal anti-inflammatory drugs. Hypersplenism (thrombocytopenia in particular) was improved. Hepatomegaly without evidence of hepatic dysfunction persisted. Enzyme replacement therapy wasn't available.

Results

Conclusion

\section{THU0163 CORTISOL AND PROLACTIN LEVELS IN RHEUMATOID ARTHRITIS AND SYSTEMIC LUPUS ERYTHEMATOSUS}

E Grabocka, A Tafaj, A Këlliçi. Clinic of Reumatology, Hospital University Center "Mother Theresa", Tirana, Tirana

10.1136/annrheumdis-2001.1065

Background Accumulated evidence suggests the existence of bidirectional communication between the neuroendocrine and immune systems. The pituitary gland can regulate the immune response secreting both immunostimulatory [e.g. prolactin $(\mathrm{PRL})]$ and immunosupressive (cortisol via ACTH) hormones. A disorder of the immunoregulatory circuit between these systems could potentially result in the development of immune mediated diseases. Hiperprolactinemia has been implicated in the pathogenesis of systemic lupus erythematosus (SLE), Reiter's Syndrome and psoriatic arthritis. Elevated PRL levels have been described in patients with rheumatoid arthritis (RA). However, clinical studies regarding the PRL level and disease activity have yielded contradictory results.

Objectives In this study our aim was to assess prolactin and cortisol plasma levels in patients with RA and SLE and to evaluate their correlation with disease activity.

Methods PRL and cortisol plasma levels were measured in 40 female patients aged (24 RA patients and 16 SLE patients) 38.88 \pm 14.44 and 40 age-matched healthy controls. Pregnant patients, patients taking drugs that could increase PRL or cortisol levels and those with renal and/or hepatic failure, were excluded from the study. All subjects were premenopausal women with regular menstrual cycles. Plasma concentrations of prolactin and cortisol were determined by radioimmunoassay under standardised conditions in venous blood drawn through an indwelling cannula. Disease activity was assessed using the Disease Activity Score (DAS) for the RA patients SLEDAI for SLE patients.

Results The mean PRL plasma level was higher in RA and SLE than in the control group $(13.8 \pm 6.1 ; 15.6 \pm 4.2$ vs. $8.78 \pm$ 2.43 , respectively, $\mathrm{p}<0.05)$. Cortisol plasma levels were found to be higher in the RA and SLE patients than in controls, but there were not significantly different $(14.2 \pm 3.6 ; 16.3 \pm 3.3$ vs. $13.1 \pm 2.8$ respectively, $\mathrm{p}>0.05$ )

Conclusion No difference was found in prolactin and cortisol levels between RA and SLE patients.

A correlation between prolactin and cortisol levels was found only in SLE patients $(\mathrm{p}<0.05)$.

No correlation was found between PRL or cortisol levels and disease activity in RA and SLE subjects.

\section{THU0164 IS SOLUBLE CD44 ISOFORM VARIANT 5 USEFUL AS PREDICTING FACTOR AND AS PARAMETER FOR LONG- TERM OBSERVATION IN RHEUMATOID ARTHRITIS?}

M Skoumal, G Kolarz, A Wottawa. Institute for Rheumatology in Cooperation with the Donau Universität Krems, Rheumasonderkrankenanstalt Der SVA Der Gewerblichen Wirtschaft, Baden, Austria

10.1136/annrheumdis-2001.1066 
Background CD44 is a widely expressed adhesion molecule responsible for cell-cell, cell-matrix interaction and binds hyaluronan and other extracellular matrix and cell surface proteins. Binding of CD44 leads to immune mediated inflammation, target lysis and tumour dissemination. Except this constant membrane bound form a variety of isoforms are expressed. Soluble CD44 variant isoform $5(\mathrm{sCD} 44 \mathrm{v} 5)$ is associated with a high rate of cell division and is elevated in patients with erosive IgM rheumatoid factor positive Rheumatoid Arthritis (RA+).

Objectives To examine whether sCD44v5 correlates with inflammation and/or joint destruction in a long-term treatment of patients with RA.

Methods Serum levels of sCD44v5 were measured in 73 patients with RA according to the criteria of ACR treated in intervals in our department in the duration of 10 years using a commercially available ELISA-test, developed by Bender-Med-Systems-Vienna. The results of sCD44v5 were compared with Disease Activity Score (DAS), 28 Joint Count (28JC), 30 Swollen Joint Count (30SJC), Ritchie Index, Proximal Interphalangeal Score (PIP), Stoke Index, Larson Score, Steinbrocker Stage, C- Reactive- Protein (CRP), Erythrocyte Sedimentation Rate (ESR), rheumatoid factor (RF) and DMARD therapy.

Results We detected elevated serum levels of sCD44v5 in 50/356 measurements, with a range from 58,4 to 312,9 . The mean sCD44v5 was $42,3 \mathrm{ng} / \mathrm{ml}$. The results showed a significant correlation with RF (mean 299,4 U/ml, p < 0,001) and a weak correlation with $\operatorname{ESR}($ mean $31,9 \mathrm{~mm} \mathrm{HG}, \mathrm{p}<0,03)$ ), but no correlation with CRP (mean 21,1 mg/l), DAS (mean 3,54) and other clinical scores. Furthermore we found no significant difference of sCD44v5 with different DMARD therapies.

Conclusion In our cohort sCD44v5 does not prove to be useful as predicting factor or indicator for a long-term treatment observation. Although sCD44v5 is known to be elevated in patients with rheumatoid flare such a correlation could not be shown in our study with weak to moderate inflamed patients. Soluble CD $44 v 5$ therefore seems to be elevated only in severe inflammation.

\section{REFERENCES}

1 Haberhauer G, Kittel EM. Soluble CD44-Isoform variant 5 (sCD44v5): a new serum marker in rheumatoid arthritis? J Rheumatol. 1998;25(7):1442-4

2 Haberhauer G, Skoumal M, Kittel EM, Bauer K, Feyertag J, Dunky A. Soluble CD44-isoform variant -5 (sCD44v5) in psoriatic arthritis. Clin Exp Rheumatol. 1998;16(6):766-7

3 Feyertag J, Haberhauer G, Skoumal M, Kittl EM, Bauer K, Dunky A. Serumspiegel löslicher CD 44-Isoform-Variante 5 von Patienten mit seropositiver RheumatoidArthritis unter Cyclosporin-A-Therapie. Acta Medica Austriaca 2000;27(5):156-9

\section{THU0165 LONGTERM OUTCOME OF AUSTRIAN PATIENTS WITH RHEUMATOID ARTHRITIS}

M Skoumal, G Kolarz, A Wottawa. Institute for Rheumatology in Cooperation with the Donau Universität Krems, Rheumasonderkrankenanstalt Der SVA Der Gewerblichen Wirtschaft, Baden, Austria

\subsection{6/annrheumdis-2001.1067}

Background Rheumatoid Arthritis (RA) is a progressive disease and is characterised by increased work disability, functional declines and radiographic damages. To prevent irreversible joint damage, Disease Modifying Antirheumatic Drugs (DMARDs) and recently available biologics should be given as soon as possible. Prospective long-term studies are difficult to organise and may have a minimal relevance for current clinical practice at the end of the study.
Objectives To examine retrospectively the long-term outcome of patients with RA in Austria.

Methods 81 indoor patients with seropositve RA (RA+) and seronegative RA (RA-) completed a standardised clinical and laboratory blood examination 3 ? $8 \times$ between 1978 ? 1999. The course of the disease was assessed by determining of Disease Activity Score (DAS), 28 Joint Count (28JC), 30 Swollen Joint Count (30SJC), Proximal Interphalangeal joint score (PIP), Ritchie Index, Stoke Index, Steinbrocker stage and Larson score. Results Over 21 years with a mean duration of follow up of 10 years we observed a statistically significant improvement of PIP, of Ritchie Index, of Stoke Index and of DAS. Steinbrocker stage and Larson Score increased significantly. With respect to DMARDs we noted that a high percentage of the patients did not receive any DMARDs within the first two years of disease. From all used drugs Methotrexate (MTX) was continued much longer and was the preferred DMARD since the early nineties. Referring to extraarticular manifestations the most frequent was Sicca Syndrome in relation with positive Antinuclear Antibodies (ANA). We found two cases of vasculitis and one case of lung fibrosis; however we did not find a case of amyloidosis.

Conclusion In our long-term follow up a change of treatment with rather weak DMARDs at the onset of the disease to a more aggressive treatment within the last decade was remarkable. With respect to the significant increase of Steinbrocker stage and Larson score as well an early aggressive therapy is however required With respect to the association of ANA and extrarticular manifestations elevated ANA should give rise for an exact organ screening. The development of predicting factors for the outcome of patients with RA would be helpful to refer patients to specialist care as soon as possible.

\section{REFERENCES}

1 Wolfe F, Hawley DJ, Cathey MA. Termination of slow acting antirheumatic therapy in rheumatoid arthritis: a 14 year prospective evaluation of 1024 consecutive starts. J Rheumatol. 1990;17:994-1002

2 Scott DL. Prognostic factors in early rheumatoid arthritis. Rheumatology 2000;39 (Suppl 1):24-9

3 Pincus T, Callahan LF, Sale WG, Brooks AL, Payne LE, Vaughn WK. Severe functional declines, work disability, and increased mortality in seventy-five rheumatoid arthritis patients studied over nine years. Arthritis Rheum. 1984;27:864-72

\section{THU0166 HIGH DIAGNOSTIC VALUE OF ANTI-FILAGGRIN AUTOANTIBODIES (AFA) DETECTED BY A NEW ELISA IN A COHORT OF 152 COMMUNITY CASES OF VERY EARLY ARTHRITIS}

${ }^{1} \mathrm{O}$ Vittecoq, ${ }^{2} \mathrm{~B}$ Inçaurgarat, ${ }^{3} \mathrm{~J}$ Legoedec, ${ }^{1} \mathrm{~A}$ Gayet, ${ }^{4} \mathrm{P}$ Fardellone, ${ }^{4} \mathrm{P}$ Boumier, ${ }^{5} \mathrm{~A}$ Phan Van, ${ }^{1} \mathrm{JM}$ Bertho, ${ }^{1} \mathrm{C}$ Zarnitsky, ${ }^{1} \mathrm{O}$ Mejjad, ${ }^{1} \mathrm{~A}$ Daragon, ${ }^{2} \mathrm{M}$ Jolivet, ${ }^{3} \mathrm{~F}$ Tron, ${ }^{1} \mathrm{X}$ Le Loët. ${ }^{1}$ Rhumatologie, INSERM U519, IFR23; '2BioMérieux, SA, Marcy I'Etoile; ${ }^{3}$ Immunologie, INSERM U519, IFR23, Rouen; ${ }^{4}$ Rhumatologie, CHU d'Amiens, Amiens; ${ }^{5}$ Rhumatologie, CHU de Tours, Tours, France

\subsection{6/annrheumdis-2001.1068}

\section{Background}

Objectives To determine the diagnostic value of autoantibodies $(\mathrm{Ab})$ directed against citrullinated recombinant rat filaggrin (ACRFA) for very early RA.

Methods From a population-based recruitment, 152 patients with early (median disease duration:4 months [2 $\square 6 \mathrm{mo}]$ ) peripheral arthritis (swelling of at least 2 joints persisting $>4$ weeks) were studied. Follow-up period was 1 year. At the end of the study, patients were classified as RA $(\mathrm{n}=88)$ or as other rheumatic diseases. Four Ab: rheumatoid factors (RF-IgM), anti-keratin $\mathrm{Ab}$ (AKA), anti-perinuclear factor (APF) and ACRFA by an 